\title{
PATOLOGIAS DAS CONSTRUÇÕES: INVESTIGAÇ̃̃O DAS MANIFESTAÇÕES PATOLÓGICAS EM CONDOMÍNIO HABITACIONAL NA CIDADE DE PARNAMIRIM-RN
}

\author{
QUEIROZ, ANNA BEATRIZ RODRIGUES DE \\ Graduanda em Engenharia Civil \\ Universidade Potiguar \\ Rio Grande do Norte; Brasil \\ beatriz.abrq@hotmail.com
}

\author{
MARQUES, MARCOS VINÍCIUS DIAS \\ Graduando em Engenharia Civil \\ Universidade Potiguar \\ Rio Grande do Norte; Brasil \\ mv.vinicius2000@gmail.com
}

\section{CRUZ, CLÁUDIA PATRÍCIA TORRES}

Professora Doutora em Física da Matéria Condensada Universidade Potiguar

Rio Grande do Norte; Brasil

claudiacruz.unp@gmail.com

\author{
SANTOS, KLLEYSON FREITAS DOS \\ Graduando em Engenharia Civil \\ Universidade Potiguar \\ Rio Grande do Norte; Brasil \\ klleysonfreitas2@hotmail.com
}

\author{
SANTOS, RODRIGO RODRIGUES DOS \\ Graduando em Engenharia Civil \\ Universidade Potiguar \\ Rio Grande do Norte; Brasil \\ rodrigorodrigues9798@hotmail.com
}

\author{
LUCENA, MAURÍLIO DE MEDEIROS \\ Professor Mestre em Engenharia Mecânica \\ Universidade Potiguar \\ Rio Grande do Norte; Brasil \\ mauriliomedeiros@unp.br
}

\section{RESUMO}

Atualmente, como a dinamização da indústria da construção civil, as empresas tem pautado suas atenções na diminuição do custo e no prazo das construções, contudo ao acelerar o tempo de execução, o que se tem registrado é o atropelamento de etapas essenciais e ausência de controle de qualidade nos materiais e serviços, o que tem contribuído para o surgimento de diversas patologias e prejuízos em decorrência de retrabalhos e eventos pós-ocupação. Daí a importância do pleno conhecimento e domínio dos processos técnicos envolvidos na construção civil (planejamento, projeto, execução, uso e manutenção), e no caso do empreendimento analisado, o melhoramento da qualidade das habitações sociais. A metodologia adotada faz uso de organização dos dados coletados em campo e catalogação das patologias através de checklist de verificação dos sistemas prediais, relatórios fotográficos, formulação de diagnósticos e planos de intervenção para as manifestações patológicas encontradas. O objetivo deste artigo é identificar e analisar as patologias existentes em unidades habitacionais, construídas em um condomínio residencial multifamiliar, situado no município de ParnamirimRN.

Palavras-chave: edifícios. diagnóstico. construções.

\section{ABSTRACT}

Currently, as the dynamization of the civil construction industry, the companies have based their attention on the reduction of cost and time of construction, however, by accelerating the time of execution, what has been recorded is the trampling of essential stages and lack of quality control in materials and services, which has contributed to the emergence of several pathologies and losses due to rework and post-occupation events. Hence the importance of full knowledge and mastery of the technical processes involved in civil construction (planning, design, execution, use and maintenance), and in the case of the project analyzed, the improvement of the quality of social housing. The methodology adopted makes use of the organization of data collected in the field and cataloguing of pathologies through check-list verification of building systems, photographic reports, formulation of diagnoses and intervention plans for the pathological manifestations found. The objective of this article is to identify and analyze the existing pathologies in housing units, built in a multi-family residential condominium, located in the municipality of Parnamirim-RN.

Keywords: buildings. diagnosis. constructions. 


\section{INTRODUÇÃO}

A construção civil vivenciou nos últimos anos uma estagnação no crescimento frente às demais áreas da indústria. Contudo, o saldo positivo registrado na produção da indústria da construção até 2013, contribuiu para o aumento no número de unidades habitacionais construídas, na última década, principalmente, as direcionadas para a população de menor poder aquisitivo. $\mathrm{O}$ aumento no número de imóveis finalizados foi motivado, principalmente, por incentivos de programas públicos, à exemplo do Minha Casa Minha Vida.

Contudo, a medida em que cresceu o número de empreendimentos construídos, percebeu-se um aumento proporcional no número de reclamações por parte dos proprietários desses imóveis, devido a insatisfação no desempenho das edificações, já nos primeiros anos de vida. Segundo a Associação Nacional dos Mutuários (2012), o registro de problemas com imóveis novos aumentou cerca de 35\% (apud GASPARIN, 2013). O aparecimento de manifestações patológicas é motivado, muitas vezes, pela necessidade de se maximizar os lucros em um mercado bastante competitivo como o da construção civil, no qual priorizou-se a redução no tempo de construção dos imóveis, deixando de lado aspectos muito mais relevantes e que poderiam contribuir para o melhoramento da qualidade dessas habitações, como é o caso do investimento de tempo em desenvolvimento de projetos mais precisos e coerentes com as questões de habitabilidade, o melhoramento dos métodos de execução e a inserção de sistemas de controle de qualidade. A ausência desses aspectos pode contribuir para o surgimento de patologias nas construções (DO CARMO, 2003).

A ciência que estuda as patologias das construções deve ser entendida como a parte da engenharia que procura compreender as razões e origens dos problemas construtivos que podem aparecer nas edificações. E assim, garantir soluções que impeçam o seu surgimento e que tais anomalias não se tornem recorrentes (ZUCHETTI, 2015).

Atualmente, observa-se um desenvolvimento tecnológico animador no campo da construção civil, no qual vem se adotando métodos e materiais que proporcionam ganhos no desempenho e na execução das edificações. Contudo, ainda é possível identificar a incidência de patologias diversas. Para Costa (2013), mesmo existindo uma crescente preocupação com a qualidade das edificações, ainda é possível verificar empreendimentos executados, nos últimos anos, sem que sejam atingidos os parâmetros de qualidade requeridas. A falta de cumprimento dessas exigências e recomendações pode contribuir para o surgimento de patologias nas construções em curto, médio e longo prazo.

Nesse cenário, faz-se necessário um maior entendimento sobre o surgimento e a evolução das patologias, além dos seus impactos no desempenho e vida útil das edificações. O surgimento de anomalias gera demanda de retrabalho, haja vista que se faz necessário uma intervenção nas regiões afetadas para solucioná-las ou, pelo menos, garantir a sua estabilização. O retrabalho implica em custos adicionais que, na maioria das obras de engenharia, não são contabilizados durante a fase de planejamento. Segundo Oliveira (2001), a repetição de erros em obras, no Brasil, se deve em parte pela falta de comunicação e envolvimento entre os profissionais projetistas, gerenciadores de obra e os gestores de manutenção.

O objetivo desse trabalho é apresentar a análise dos sistemas construtivos de uma edificação, dando ênfase às manifestações patológicas de maior incidência. Bem como, subsidiar elementos para a execução de futuros reparos e/ou restaurações com intuito de devolver aos sistemas prediais uma boa funcionalidade. Para tanto, pretende-se, ao término dessa avaliação, disponibilizar aos responsáveis pelo condomínio residencial as análises, conclusões e recomendações para a realização de manutenções, reparos e recuperações específicas a cada grupo de patologia.

\section{METODOLOGIA}

O estudo foi realizado em um condomínio residencial multifamiliar, localizado na cidade de Parnamirim/RN. O residencial é composto por 18 torres de 04 pavimentos, sendo 01 pavimento térreo e 03 pavimentos tipo, distribuídas em 09 blocos. Cada torre possui 04 apartamentos por andar, totalizando 16 (dezesseis) apartamentos e 288 (duzentos e oitenta e oito) imóveis individuais em todo o complexo.

O trabalho de campo teve início com uma visita aos imóveis, na qual foi realizada a vistoria técnica, com o objetivo de catalogar as anomalias, analisar e processar os dados coletados in loco. A análise foi realizada de forma pormenorizada, sob a ótica sistêmica tridimensional (quanto à técnica, ao uso e à manutenção).

A catalogação e processamento dos dados foram realizados durante a vistoria, na qual foram empregados check-lists de verificação dos sistemas, conforme apresentado na Figura 1. 
Empregou-se ainda registro fotográfico das regiões de interesse para que, em momento posterior, fosse executada a análise preliminar das manifestações (falhas e/ou anomalias). Ao fim das ações de campos, realizou-se a confrontação dos dados coletados com as recomendações normativas e de manuais de execução específicas a cada sistema de construção, objetivando o levantamento das condições relativas à integridade dos elementos construtivos. Após o levantamento dos dados, foi possível realizar um feedback aos responsáveis pelo condomínio residencial com conclusões e recomendações de manutenções e reparos.

\begin{tabular}{|c|}
\hline CHECK-LIST PARA VISTORIA DE IMÖVEL \\
\hline Resp. Vistoria: \\
\hline Bairro: \\
\hline Proprietário (a): \\
\hline $\begin{array}{l}\text { Há fisgura éou trinca em canto de våo de esquadria? } \square \text { Sim } \square \text { Năo } \\
\text { Local: }\end{array}$ \\
\hline $\begin{array}{l}2 \text { Há fisgura e/ou trinca em parede? } \square \text { Sim } \square \text { Não } \\
\text { Local: }\end{array}$ \\
\hline $\begin{array}{l}3 \text { Há fissura e/ou trinca em forro de gesso? } \square \operatorname{Sim} \square \text { Não } \\
\text { Local: }\end{array}$ \\
\hline $\begin{array}{l}4 \text { Há trinca ou destacamento de revestimento cerâmico? } \square \text { Sim } \square \text { Não } \\
\text { Local: }\end{array}$ \\
\hline $\begin{array}{l}5 \text { Há infiltração ascendente em parede? } \square \operatorname{Sim} \square \text { Não } \\
\text { Local: }\end{array}$ \\
\hline $\begin{array}{l}6 \text { Há infiltração em forro? } \square \operatorname{Sim} \square \text { Não } \\
\text { Local: }\end{array}$ \\
\hline $\begin{array}{l}7 \text { Há infiltração descendente em parede? } \square \operatorname{Sim} \square \text { Não } \\
\text { Local: }\end{array}$ \\
\hline $\begin{array}{l}\text { Há infiltração descendente em janela? } \square \operatorname{Sim} \square \text { Não } \\
\text { Local: }\end{array}$ \\
\hline $\begin{array}{l}9 \text { Existe porta inapropriada para o ambiente? } \square \text { Sim } \square \text { Näo } \\
\text { Local:_. }\end{array}$ \\
\hline $\begin{array}{l}10 \text { Há esquadria (porta efou janela) deteriorada? } \square \text { Sim } \square \text { Não } \\
\text { Local: }\end{array}$ \\
\hline $\begin{array}{l}11 \text { Existe dispositivo hidrosganitário danificado? } \square \operatorname{sim} \square \text { Não } \\
\text { Dispositivo: }\end{array}$ \\
\hline 12 Existe dispositivo residual (DR) na residência? $\square$ Sim $\square$ Não \\
\hline $\begin{array}{l}13 \text { Há instalação de ponto elétrico exposto à água e/ou compartilhamento de eletroduto? } \square \text { Sim } \square \text { Não } \\
\text { Local:- }\end{array}$ \\
\hline $\begin{array}{l}14 \text { Há janela com capiaço de inclinação inadequada (falha/ausência de pingadeira)? } \square \text { Sim } \square \text { Näo } \\
\text { Local: }\end{array}$ \\
\hline
\end{tabular}

Figura 1: Check - list usado para realizar as vistorias.

Fonte: Autores, 2019. 
A Figura 2 apresenta as ferramentas aplicadas na análise das manifestações patológicas das construções.

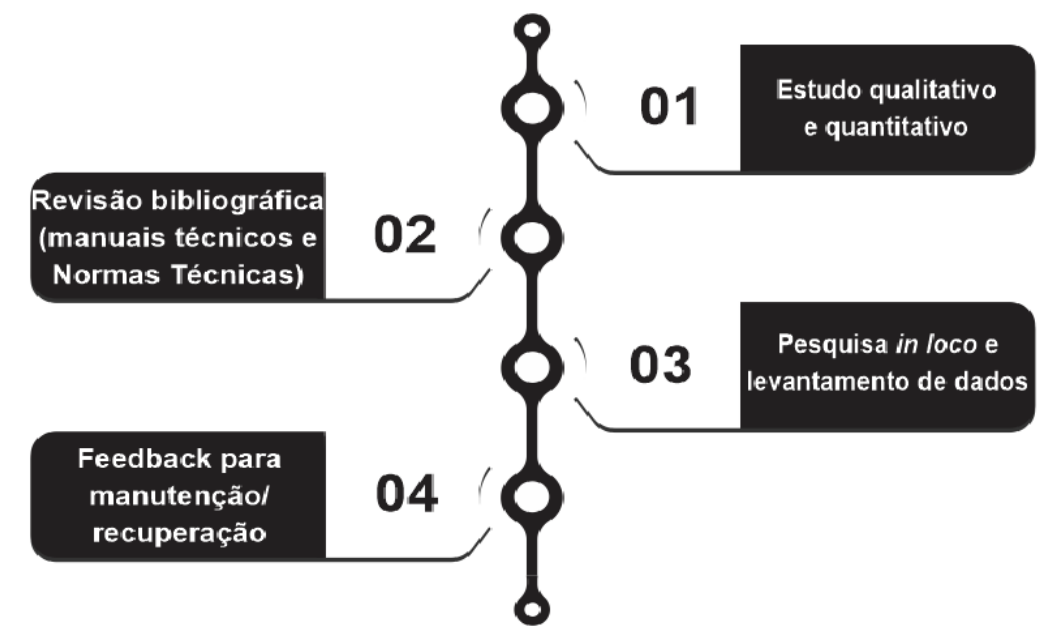

Figura 2: Fluxograma da metodologia.

Fonte: Autores, 2019.

\section{RESULTADOS E DISCUSSÕES}

A análise feita in loco das condições dos imóveis permitiu a constatação da existência de algumas anomalias incidentes sobre impermeabilização, painéis de alvenarias de vedação, revestimentos de parede, esquadrias, pintura e sistema elétrico.

As alvenarias de vedações apresentaram fissuração na região de interface com a estrutura de concreto armado, devido à falha na solidarização entre a alvenaria e o sistema estrutural do edifício. Observou-se também que as regiões das fachadas dos edifícios que possuem incidência direta do sol apresentam problemas com abertura de fissuras e trincas. Neste caso, os elementos foram dimensionados apenas para desempenhar função de isolação vertical e divisão de ambientes, desencadeando a abertura de fissuras e trincas.

A fissuração das vedações compromete a estanqueidade da alvenaria, possibilitando a infiltração de água, proliferação de mofo e bolores, além de danos aos revestimentos e deterioração dos painéis de alvenaria. A seguir, é apresentado na Figura 3 o registro fotográfico da ocorrência de abertura de fissuras em painel de alvenaria com abertura de vão de esquadria.

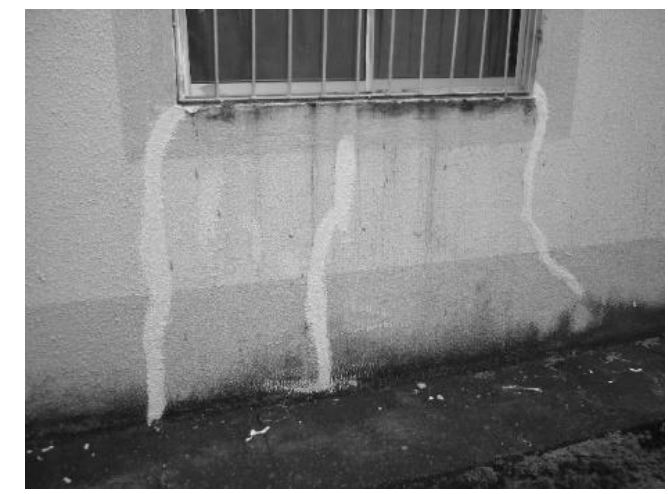

Figura 3: Fissuras corrigidas.

Fonte: Autores, 2019. 
Foram identificadas manifestações de eflorescência na base das alvenarias, em decorrência da ascensão da água por capilaridade. A água não estanque pelo sistema de impermeabilização acaba sendo absorvida e ascende através dos poros dos blocos da alvenaria e pela própria argamassa utilizada. A Figura 4 apresenta o registro de eflorescência em alvenaria do condomínio residencial analisado.

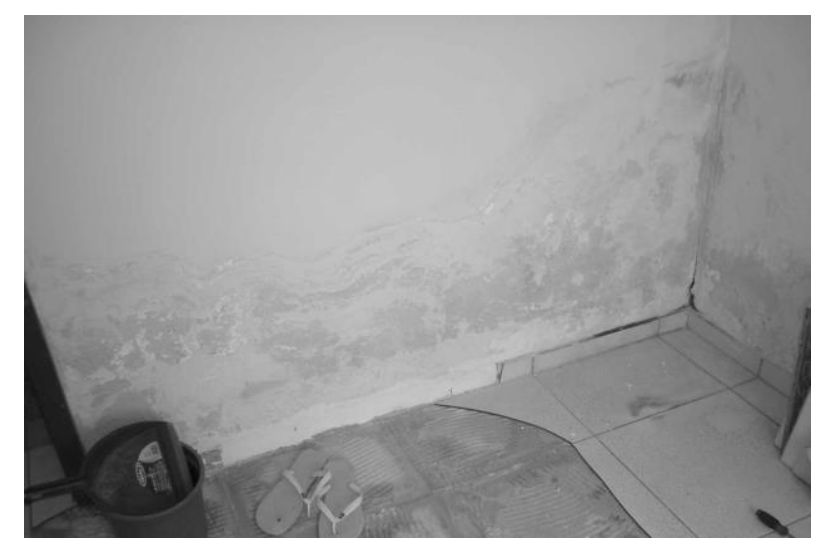

Figura 4: Eflorescência em alvenaria. Fonte: Autores, 2019.

Foi identificado em algumas unidades habitacionais o desnivelamento de placas dos revestimentos de gesso e fissuras entre peças, além do desplacamento como decorrência da umidade de infiltrações provenientes das falhas do sistema de impermeabilização do apartamento imediatamente superior, conforme apresentado na Figura 5. A ocorrência dessas manifestações diminui o desempenho desse sistema construtivo, tanto nos aspectos estéticos quanto em relação às funções de proteção e isolamento.

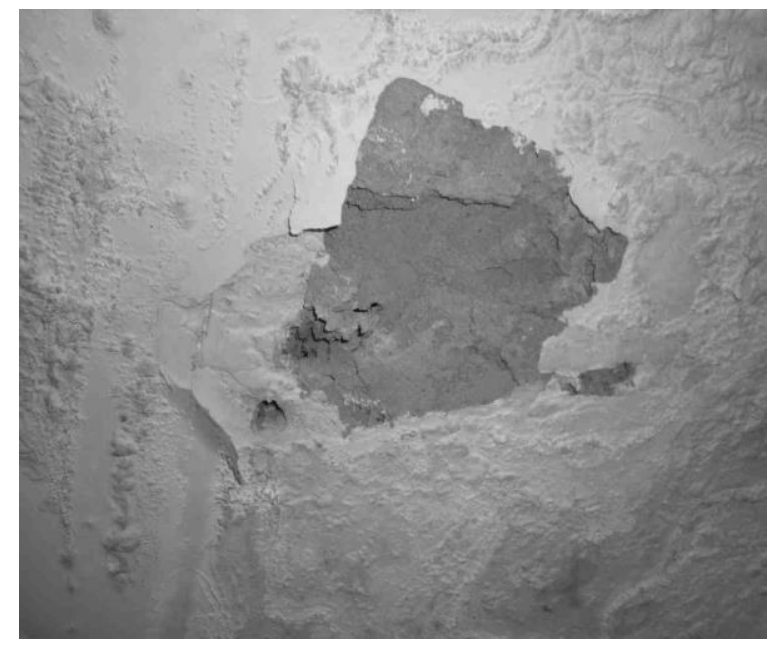

Figura 5: Desplacamento do gesso.

Fonte: Autores, 2019.

Este fenômeno ocorre pela falha do sistema de contenção da umidade das fundações, bem como da impermeabilização da base da alvenaria a uma altura mínima de 0,30m em relação ao piso e das áreas molháveis (AZEREDO, 2004). Como resultado da exposição contínua do bloco cerâmico à umidade, é observado uma redução no seu desempenho mecânico (ANDRADE, 2009) e, consequentemente, na vida útil desse elemento construtivo.

Em função do aparecimento de fissuras e das infiltrações, a camada de pintura é igualmente danificada seguindo a mesma sistemática de degradação dos demais sistemas a ele associados. Verificou-se a ocorrência de manifestações patológicas em pinturas decorrentes da aplicação em superfícies não estabilizadas, superfícies deterioradas ou substrato não adequado para aplicação da pintura. 
A condição climática que mais colaborou para o surgimento de anomalias nesse tipo de revestimentos foi a exposição acentuada à umidade, que acelerou o desgaste da camada da pintura. Na Figura 6 observa-se a manifestação encontrada no revestimento de pintura, que apresenta manchas de umidade, eflorescência, fissuras e desplacamento da película de pintura.

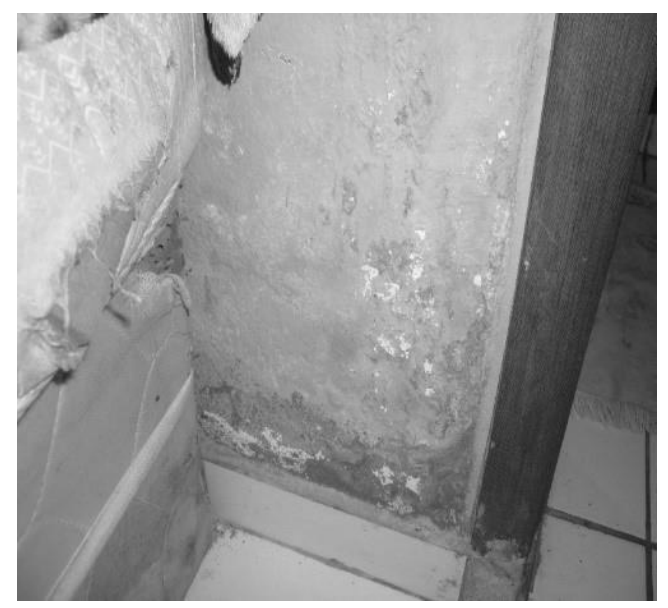

Figura 6: Manchas e desplamento da pintura.

Fonte: Autores, 2019.

Foi registrada a degradação da esquadria do banheiro motivada pela exposição prolongada à umidade. $\mathrm{O}$ material componente da esquadria, nesse caso a madeira, não apresenta boa resistividade à frequente ação da umidade promovida nesse ambiente, partindo das regiões próximas ao piso e atingindo a folha da porta, a caixa e os alisares, nos quais é visível o processo de apodrecimento em decorrência da presença de água, conforme ilustrado na Figura 7.

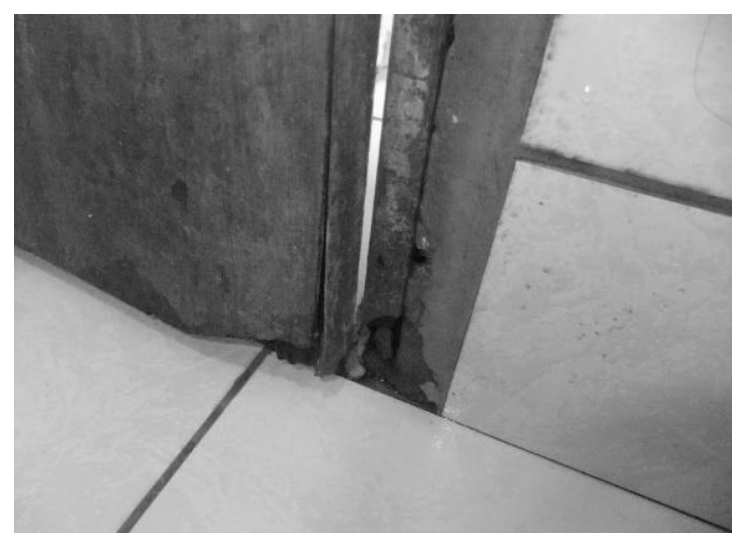

Figura 7: Apodrecimento da madeira da esquadria. Fonte: Autores, 2019.

Foram identificados problemas no sistema elétrico e telefônico dos imóveis, diretamente relacionados a não observância das recomendações técnicas da ABNT NBR 5410:2004 - Instalações Elétricas de Baixa Tensão. Um dos problemas registrados e que se manifesta em um número considerável de unidades vistoriadas é a obstrução dos eletrodutos dos pontos de TV, que não permitem a passagem dos cabos e acabam por inabilitar o funcionamento do sistema. $\mathrm{O}$ circuito de iluminação do banheiro apresenta a instalação do ponto de acionamento da luminária a uma distância inferior a $0,60 \mathrm{~m}$, o que acaba por contrariar a ABNT NBR 5410:2004 e impõe risco de choque elétrico aos proprietários, conforme apresentado na Figura 8. 

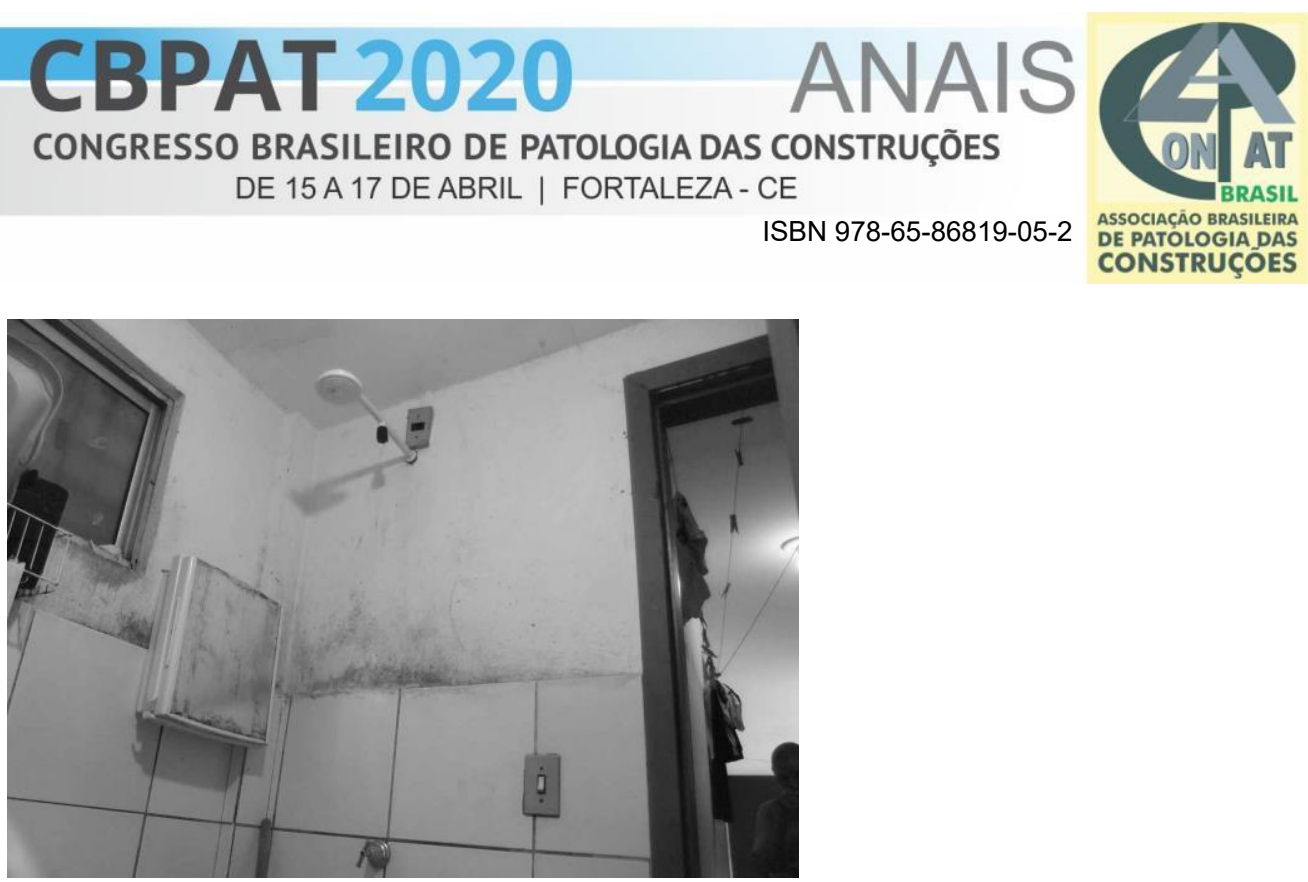

Figura 8: Instalações inadequadas.

Fonte: Autores, 2019.

A Figura 9 apresenta a análise dos dados coletados na pesquisa de campo que permitiu determinar os sistemas construtivos mais afetados pelas manifestações patológicas. O sistema de revestimento é o mais afetado devido a influência do sistema de impermeabilização mal executado ou, em alguns casos, inexistente.

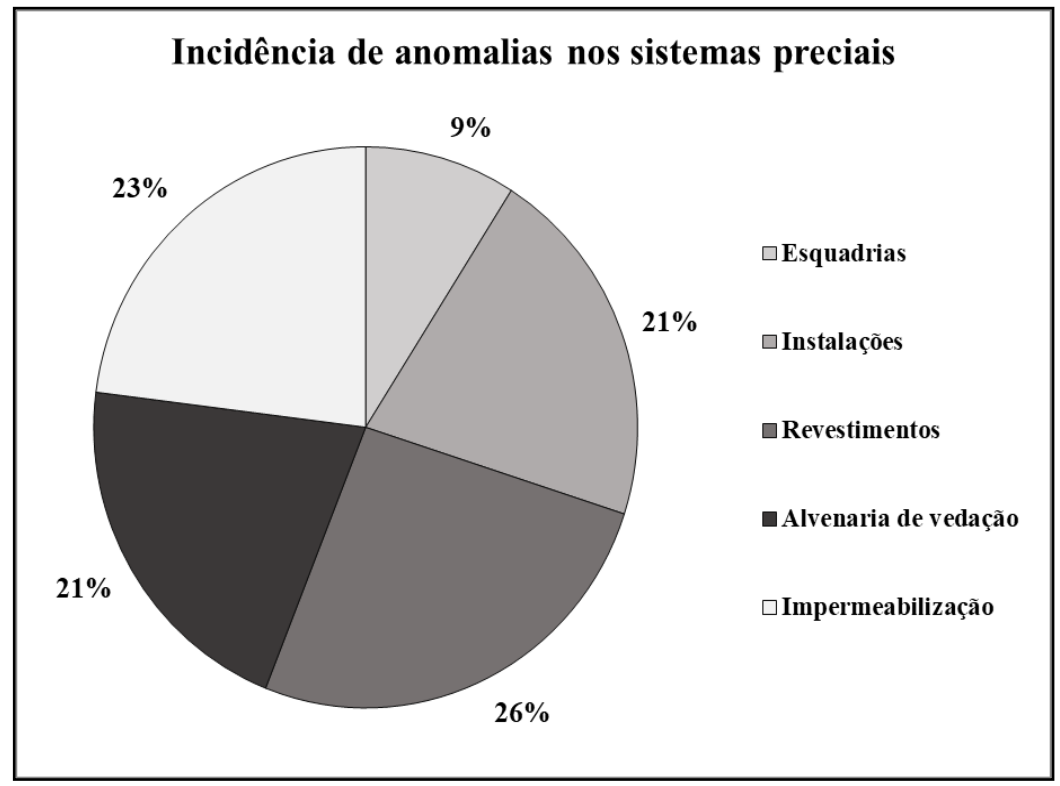

Figura 9: Incidência de anomalias nos sistemas prediais.

Fonte: Autores, 2019.

A correlação dos sistemas construtivos afetados devido a etapa de construção (concepção, planejamento, execução, uso e manutenção) do empreendimento estudado é apresentado na Figura 10. Os erros na fase de execução dos serviços, escolha dos materiais e mão de obra são as principais causas para o surgimento de manifestações patológicas. 


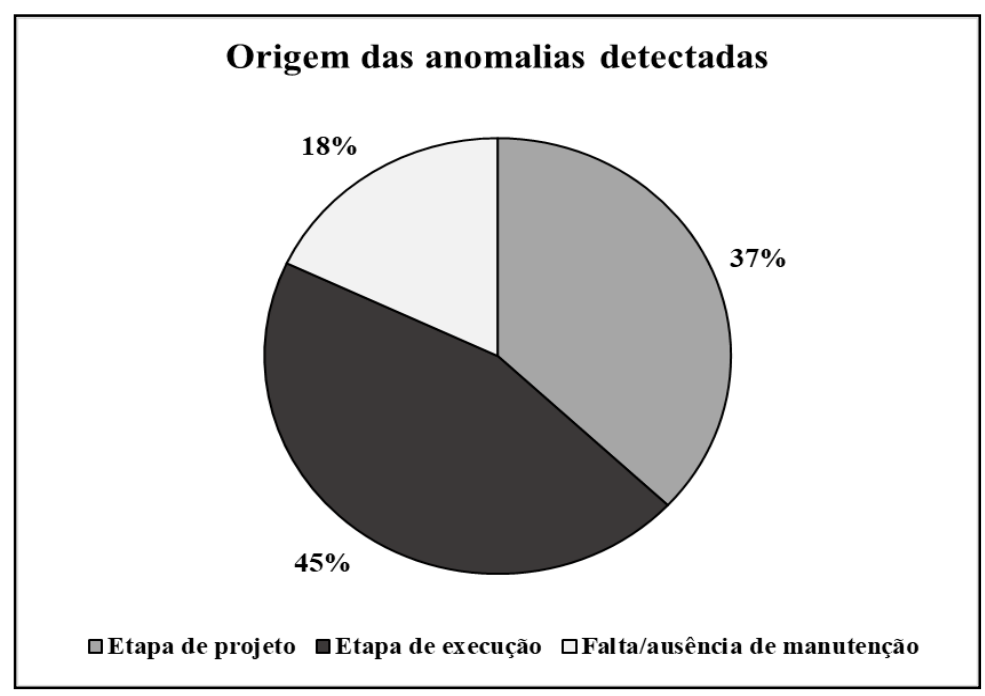

Figura 10: Origem das anomalias detectadas. Fonte: Autores, 2019.

Na Figura 11 é apresentada a existência de intervenções relativas à manutenção nas unidades habitacionais do empreendimento em estudo. A ausência de intervenções mínimas colabora para o agravamento das manifestações já existentes e, consequentemente, para o surgimento de demais manifestações.

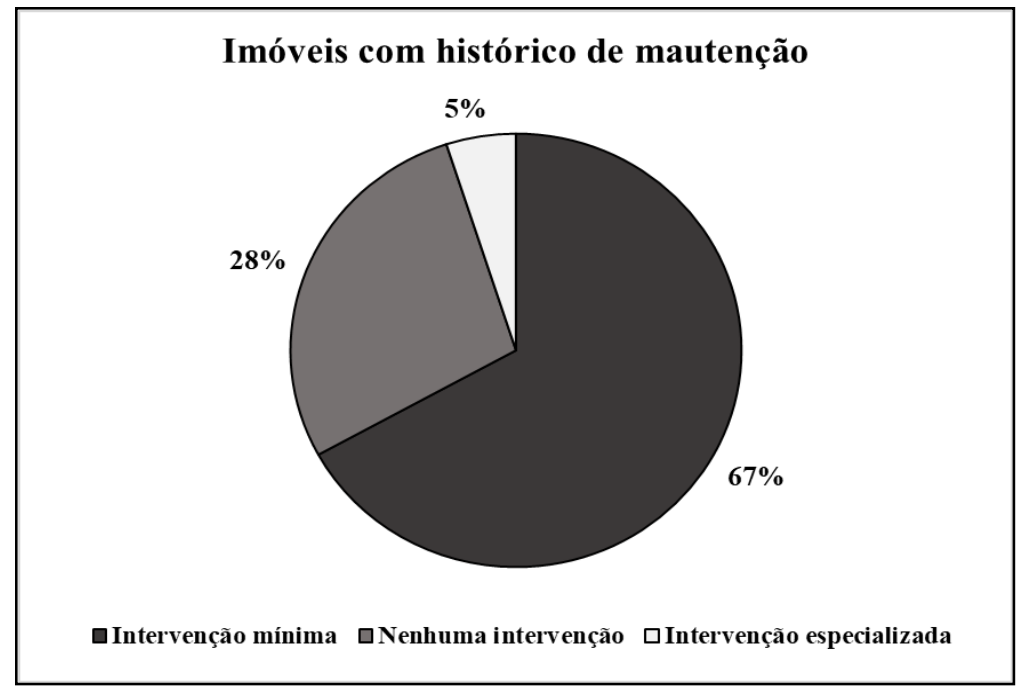

Figura 11: Imóveis com histórico de manutenção.

Fonte: Autores, 2019.

\section{CONCLUSÃO}

Foram constatadas manifestações patológicas nas unidades inspecionadas, abrangendo diferentes sistemas da construção, relacionados a erros de planejamento, projeto e execução. As anomalias identificadas ocasionaram e continuam a provocar danos consideráveis aos imóveis e aos indivíduos que ali residem, dado o grau de deterioração de alguns dos sistemas prediais e pela presença de microrganismos (mofo e bolor) em algumas delas. Os danos podem ser classificados em três categorias: a redução da durabilidade e vida útil da edificação, diminuição da segurança na utilização dos imóveis e redução da salubridade e habitabilidade das unidades habitacionais.

É notória a utilização de materiais inadequados à sua finalidade, bem como, a incidência de falhas de concepção de projeto, além do emprego de técnicas construtivas equivocadas, o que tem contribuído para a redução da durabilidade e vida útil do imóvel. Os sistemas construtivos que apresentaram manifestações patológicas podem estar relacionados com a etapa de construção, desde concepção e planejamento do projeto, execução, uso e manutenção do empreendimento. 
Diante das anomalias e falhas identificadas que podem prejudicar as unidades habitacionais de diversas maneiras, faz-se necessária uma intervenção ampla nos elementos construtivos danificados. A inexistência da execução de manutenções nos empreendimentos está intimamente ligada à ocorrência de problemas já nos primeiros anos de utilização desses imoveis. Segundo o manual de inspeção predial do IBAPE, após 05 anos de uso, todos os sistemas construtivos devem passar por um check-up preventivo para detecção de possíveis anormalidades.

O estudo realizado possibilitou aprimorar o conhecimento das manifestações patológicas e permitiu perceber a importância da promoção de intervenções preventivas para garantir a plenitude das interações sadias entre os diversos componentes da edificação. Para estudos futuros faz-se necessário identificar maiores aspectos que influenciam na ocorrência das manifestações patológicas para que sejam elaborados planos de manutenção para recuperar o sistema afetado e reduzir danos à construção e aos indivíduos.

\section{REFERÊNCIAS}

ABNT, ASSOCIAÇÃO BRASILEIRA DE NORMAS TÉCNICAS. NBR 5410. Instalações elétricas de baixa tensão. Rio de Janeiro, 2004.

ANDRADE, R. A. "Efeito da ação de carbonatos sobre a expansão por umidade associada às propriedades cerâmicas de blocos destinados à construção civil", Tese Dr., Coordenação de Pós-Graduação em Engenharia de Processo, UFCG, Campina Grande, PB (2009). Disponível em: < file://C:/Users/beatr/OneDrive/Documentos/PET/CBPAT\%20\%202020/ROBERTO\%20ALVARES\%20DE\%20AND RADE\%20-\%20TESE\%20PPGEP\%202009..pdf > Acesso em: 21 de setembro de 2019.

AZEREDO Jr, H. A. O edifício e seu acabamento. São Paulo: Edgard Blücher, 2004.

COSTA, Pedro Laranja d'Araujo. Patologias do processo executivo de revestimentos de fachada de edifícios. Rio de Janeiro: Universidade federal do rio de Janeiro, 2013.

DO CARMO, Paulo Obregon. Patologia das Construções. Santa Maria, Programa de atualização profissional - CREA - RS, 2003.

GASPARIN, Gabriela. Crescem queixas sobre defeitos em imóvel novo; veja direitos de cliente. G1, 2013. Disponível em: < http://g1.globo.com/economia/seu-dinheiro/noticia/2013/01/crescem-queixas-sobre-defeitos-em-imoveis-novos-veja-direitosde-cliente.html>. Acesso em: 21 de setembro de 2019.

OLIVEIRA, O. J, GOZZI, S. Sistema de Gestão da Qualidade em Empresas de Construção: Um Estudo de Caso. In: Seminários Avançados de Administração dA FEA/USP. São Paulo: FEA/USP, 2001.

ZUCHETTI, P. A. B. Patologias da construção civil: investigação patológica em edifício corporativo de administração pública no Vale do Taquari/RS. 2015. Trabalho de conclusão de Curso. Disponível em: <https://m.univates.br/bdu/bitstream/10737/939/1/2015PedroAugustoBastianiZuchetti.pdf> Acesso em: 21 de setembro de 2019. 